\title{
The Legal Framework of UTM for UAS
}

\author{
Richard Ryan \\ Cranfield University \\ United Kingdom \\ r.ryan@cranfield.ac.uk
}

\author{
Saba Al-Rubaye \\ Cranfield University \\ United Kingdom \\ s.alrubaye@cranfield.ac.uk
}

\author{
Graham Braithwaite \\ Cranfield University \\ United Kingdom \\ g.r.braithwaite@cranfield.ac.uk
}

\author{
Dimitrios Panagiotakopoulos \\ Cranfield University \\ United Kingdom \\ d.panagiotakopoulos@cranfield.
}

$$
\underline{\text { ac.uk }}
$$

\begin{abstract}
It is very apparent that the legal framework for Unmanned aircraft system Traffic Management (UTM) needs to be developed as regulators grapple with issues that relate to legal responsibility and accountability for each UTM stakeholder as the proliferation of drones increases. There is a considerable 'legal lacuna' that exists creating much uncertainty within the industry with respect to investment and the direction of innovation. Drones are being utilised today under controlled conditions as technology and ability develops, but with this accelerated pace of technological development, existing regulations soon become limited to address new capabilities and thus become out of date. Policy has become law in many jurisdictions, but policy needs to be developed further to keep pace with demand because safety is paramount. This paper investigates and highlights legal aspects that a regulator and UTM stakeholders have to consider in developing good drone law. It is essential that a properly considered legal framework is developed for many reasons including, but not limited to, increased positive public perception, proliferation of innovation of use cases for Unmanned Aerial Systems, improved environmental impact and improved safety. This paper describes the fundamentals that a well designed and considered legal framework for a UTM system should address, in order to provide much needed certainty that can guide all stakeholders to a regulatory path that leads to safe maximized utility of drones in shared airspace.
\end{abstract}

Keywords-Unmanned Aerial Vehicle (UAV), Unmanned Aerial System (UAS), Drone Law, Unmanned Aircraft System Traffic Management (UTM), U-space, aviation regulation, Federal Aviation Administration (FAA), European Aviation Safety Authority (EASA), UK Civil Aviation Authority (CAA).

\section{INTRODUCTION}

It is currently the case, that law is formed from policy and policy is generally formed from established principles. We are at the beginning of a legal journey, whereby we can properly form good law with respect to Unmanned Traffic Management (UTM) that is fair and equitable, in accordance with International Civil Aviation Organisation's (ICAO) principle on UTM (2019) "access to airspace should remain equitable"[1]. There are currently many competing stakeholders in the UTM environment that are not subject to a legal framework, such as UAS service providers as defined by the Federal Aviation Authority (FAA) because the legal framework does not exist. Similarly, the same applies in other jurisdictions. The aim of this paper is to identify legal issues that affect the 'UTM construct' and provide solutions for regulators to consider what will form policy and/or law.

Contrary to a well-developed legal framework for conventional Air Traffic Management (ATM), the regulatory landscape is absent when determining legal liability, obligations and responsibilities within the UTM space. There is a significant 'legal lacuna' that is not yet evident to industry because it is not fully developed as a common system and also because not all new entrants have an awareness of conventional ATM and aviation. The novel aspect of this research is the ability to identify how future regulation will define legal liability in the future, which will be affected by the specificity of how different regulators perceive opportunity and risk differently. This is contrasted with the obligation provided by the preamble to the Chicago Convention (1944) which states that "...The future development of international civil aviation... may be developed in a safe and orderly manner," that should be conjoined with the International Civil Aviation Organization's (ICAO) UTM principle "...UTM remains the responsibility of the regulator...."

Additionally, this aspect of research will have implications for many other stakeholders. The industry, which includes many original equipment manufacturers and/or software developers are ultimately 'solution developers'. They will always be looking at regulation to ensure that their products and/or services are compliant with regulatory requirements and guidelines. The absence of such causes a great degree of uncertainty, market fragmentation and business risk, which threatens to stifle the pace of innovation and preventing the unlocking of the full potential of the drone market.

\section{UTM LEGAL ISSUES}

A significant legal challenge is how the regulator is going to legislate a framework of UTM operations, whilst, for example, not stifling the development of Beyond Visual Line of Sight (BVLOS). Primarily, we're concerned with the challenges posed to a regulator. This would be the National Supervisory Authority (NSA), which would be the Civil Aviation Authority (CAA) in the UK for example. In the future, this will certainly include local authorities as airspace planning becomes complex for want of local considerations. The issue of delegated airspace planning will become significantly important as UTM develops and matures. Each regulator will undoubtedly view control of the airspace differently and may opt for a completely centralised approach to regulation, or may indeed opt for a federated approach; thereby divesting inherent risks. For example, UAS operators and others, such as NASA's TCL4 UTM programme, are seeking to establish protocols for routine BVLOS that may form the bedrock of future legislation as this will provide regulators with necessary insight.

Regulators have certainly sought in some jurisdictions to understand what it is that is required in order to facilitate UTM. The FAA has certainly identified a need for UTM; "integration of low altitude UAS operations into the NAS presents a variety of issues and novel challenges... The number of daily operations could potentially reach into the millions, taxing the NAS well beyond its current service requirements... Given the number, type, and duration of UAs operations envisioned, the existing AirTraffic Management (ATM) System infrastructure and associated resources cannot cost effectively scale to deliver services for UAS [2]. The FAA have clearly recognised and accepted that they have a responsibility to develop a regulatory framework that provides a platform for safe UAS operations. Ultimately, operating rules have to be established to make sure that all stakeholders are accountable by seeking a balance that promotes efficient and safe access to airspace for all users, manned and unmanned. This is a clear diversion from what has traditionally been in place, insofar as manned aviation is concerned, because we may be relying on unmanned aviation and their increasingly autonomous systems that comply with conflict protocols to avoid collisions in the air and with the ground. 
In relation to European Union Aviation Safety Agency (EASA), which has had a number of workshops over the last few years, they recognised the need to address the issues of ensuring safe drone traffic management by integrating drones safely into the existing air-traffic environment and the challenges that that proposition posed. EASA have subsequently developed a preliminary draft regulatory framework which contains high level safety requirements on the establishment of U-space [3]. The framework is designed to fit within the principles of harmonisation within the European Union, so the purpose of the framework was and is to enable competent authorities to set performance requirements, environmental objectives, high-level requirements for U-space services, and certification for service providers in order to satisfy traffic density and complexity of unmanned operations. The question of what is a 'competent authority' should always remain as far as legislatures are concerned. In a workshop in 2019 [4] the conclusion reached in relation to why have a separate U-space regulation is needed and not use existing rules was:

"there is a need for a separate U-space regulation to reflect the innovative character and the paradigms shift, distinct from, yet building on other aviation safety regulations; e.g. ATM present regulatory framework; there is a need to define: flight rules and airspace where U-space services will apply; roles and responsibilities of the actors, what applies and who is affected [5]"

It is clear when looking at both the FAA and EASA, there is a strong desire to understand how to regulate a burgeoning industry. It is also clear that the need for regulation is apparent in order to provide certainty, as this helps the industry determine what level of investment is required, but also there is a need of a degree of flexibility in regulation to ensure that innovation is not unnecessarily compromised. This is a challenge with any regulation, because too much regulation usually means that it becomes too expensive for new entrants to enter the market (as it is typical in conventional air-traffic management) and also for commercial operators to adapt and overcome such legal challenges. Interestingly, one of the conclusions that came out of the EASA workshop, was that the ICAO framework should not be disregarded with respect to forming a U-space regulatory framework [6].

Legislators clearly need to understand, and to some extent do, that there is a disconnect between the existing regulatory framework and the new framework that is required. This is because the existing framework was based on a different set of facts that pertain to technological advancements. As we have seen from many different types of aviation laws over the years, we see many amendments and/or many interesting aviation regulation deviations that attempt to keep up with technology, such as the Civil Aviation Act in the UK that began life in 1949 and has suffered hundreds of amendments. With respect to UTM, there is a clear need to design unique laws that deal with this unique situation; and additionally deal with uncertainty that relates to all stakeholders as detailed in the FAA's ConOps version 2 (see Figure below) in relation to activities, relationships, and conflict of laws. It's also a consideration, especially in the UK, as to how local law in the form of new/existing bylaws may affect new law as it relates to UTM. For example, there are rules as to how a byelaw may be implemented so as not to duplicate existing rules. The London Ports Authority purport to have a byelaw in place to prevent drones flying over the River Thames in London, but there is no reference to such byelaw on their website. The regulator should ensure that there is no duplication of existing legislation by local authorities or quasi-government bodies as this undermines the basis of considered state legislation and creates an environment of increased costs in a bureaucracy that acts as a barrier to market for many stakeholders.

Legislatures really do need to understand how to evaluate the effectiveness of the regulation that they are seeking to put in place. A key aspect of UTM regulation, as with any drone regulation, is safety. Ultimately, what is the question set that needs to be answered in order to establish a regulatory framework that specifically relates to a safe UTM system? EASA and the FAA in the last few years have sought to address what regulation is required, as specified in Table 1:

Table I - UTM Regulator Question Set

\begin{tabular}{|l|l|}
\hline EASA [6] & $\begin{array}{l}\text { FAA (with NASA formed the } \\
\text { UTM Research Transition } \\
\text { Team (RTT) Plan [7]) }\end{array}$ \\
\hline $\begin{array}{l}\text { What is the U-space and what } \\
\text { is the objective of the } \\
\text { regulation? }\end{array}$ & $\begin{array}{l}\text { How do we safely enable } \\
\text { widespread civilian small } \\
\text { Unmanned Aircraft Systems } \\
\text { (sUAS) operations at lower } \\
\text { altitudes? }\end{array}$ \\
\hline $\begin{array}{l}\text { Why a separate U-space } \\
\text { regulation and not use existing } \\
\text { rules? }\end{array}$ & $\begin{array}{l}\text { How do we perform } \\
\text { conceptual and technical } \\
\text { research that can be } \\
\text { transferred to the FAA? }\end{array}$ \\
\hline $\begin{array}{l}\text { How can U-space be } \\
\text { established? }\end{array}$ & $\begin{array}{l}\text { How do we identify and } \\
\text { implement UTM capabilities } \\
\text { that meet NAS service } \\
\text { expectations? }\end{array}$ \\
\hline $\begin{array}{l}\text { What is the relation between } \\
\text { U-space and ATM? }\end{array}$ & $\begin{array}{l}\text { How do we validate a research } \\
\text { UTM concepts with partners? }\end{array}$ \\
\hline $\begin{array}{l}\text { What are the U-space services } \\
\text { that need regulation? }\end{array}$ & $\begin{array}{l}\text { What is required to develop } \\
\text { and evaluate complex } \\
\text { operations at each Technical } \\
\text { Capability Level (TCL) }\end{array}$ \\
\hline $\begin{array}{l}\text { What organisations may } \\
\text { become U-space service } \\
\text { providers? }\end{array}$ & $\begin{array}{l}\text { For each TCL, what are the } \\
\text { risk orientated metrics? }\end{array}$ \\
\hline $\begin{array}{l}\text { What are the basic rules that } \\
\text { would apply in the U-space? }\end{array}$ & $\begin{array}{l}\text { How is U-space expected to be } \\
\text { financed? }\end{array}$ \\
\hline
\end{tabular}

This question set is interesting to see and analyse, because it indicates the risk profile and appetite of how countries are approaching the development of a regulatory framework. EASA have sought to develop a number of workshops with various stakeholders to arrive at a question set as described above. The FAA, on the other hand, sought to use the practical experience of NASA in their research to develop an understanding of the practical framework. In order to get to a legal framework, it is essential for the regulator to understand and learn from the outcomes of a controlled testing environment, such as the UK CAA's Innovations Sandbox[8]. The testing environment for a regulatory sandbox is based on the following:

"you have developed concepts and conducted research for your novel solution.

You have tested and approved its feasibility in a controlled environment. Now, you want to conduct trials under real-world conditions... You are unable to get regulatory approval because your solution does not fit within the scope of current regulations.

Innovative solutions, with many questions in terms of safety, security, and consumer protection...

The rectory sandbox provides you with the capability to test and trial your innovative solutions in a safe environment... You help us to define the requirements that will guide the approval you need... Help us to shape the future regulations that will support the commercial operations of your innovative solution." [Emphasis added]

When one overlays the question set that specifically relates to a regulatory framework of UTM that is required of a regulator, it would at least be a useful discussion to understand what criteria 
has been used for the evaluation of a regulatory regime. It is clear in the UK for example, that the drone bill [9] which is due to be passed into law in 2020 has not abided by a broad criterion as it currently stands. Even members of the House of Lords have been recorded as stating that it is bad law. Suggested criteria for the evaluation of a regulatory regime may include all or some of the following, as specified in Table II:

Table II: Criteria for regulatory regime

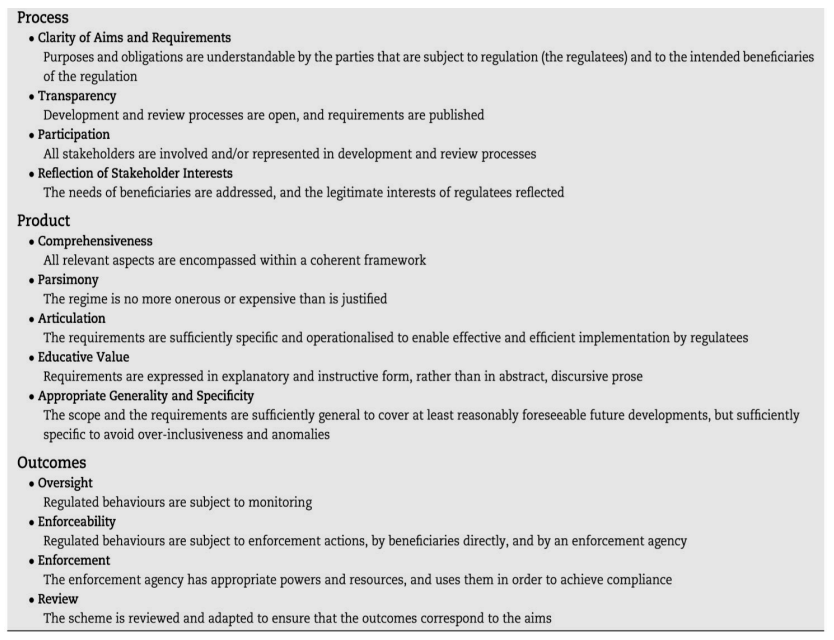

The current situation is that all stakeholders are looking for the regulators to provide guidance and yet the regulators are looking to the industry to provide expert guidance on what would be deemed acceptable and possible. What comes first? Chicken or the egg? It is not clear what criteria legislatures or regulators are utilising to develop drone law or indeed a regulatory framework for UTM. This is against the backdrop of developing state and local laws that regulate the use of UAS [10]. The development of local laws is certainly having an impact upon how the industry develops and adapts to changing market conditions as local authorities assess and determine their capability as future airspace planners [11]. What this will involve is a number of complex layers of different laws that will apply to commercial drone operators:

For example, it is anticipated that there will be an increase in new/existing, as spisified in Tbale III:

1. Federal/national law (in the case of EU member states, this will be formed by the EU for implementation by individual member states);

2. local/state law;

3. other regulations as they apply due to the requirements of UTM;

4. other non-aviation related laws and regulations;

5. the complexity of the contractual matrix that underpins the roles and responsibilities of various stakeholders within a UTM system.

Demonstrative of a step change in an increase in legislation, are the regulations that were due to come into force in the EU on 1 July 2020; which have now been postponed until 31 December 2020 [13], as shown in Fig.1. In the UK, the inception of new regulations were postponed to November 2020 and have now subsequently been aligned to the EU. Interestingly, because of Brexit, the U.K.'s transition period concludes on 31 December 2020, when the UK also leaves the regulatory regime of EASA [14].
Table III -Stakeholder Legal Accountability

\begin{tabular}{|c|c|c|c|}
\hline Stakeholder & Fed/State law & Local law & Contract \\
\hline UAS Operators & $\begin{array}{l}\text { Yes }- \text { most } \\
\text { jurisdictions }\end{array}$ & $\begin{array}{l}\text { Some - } \\
\text { inconsiste } \\
\text { nt }\end{array}$ & Some \\
\hline Local Authorities & $\begin{array}{l}\text { Power to } \\
\text { impose byelaws }\end{array}$ & $\begin{array}{l}\text { Some - } \\
\text { different } \\
\text { applicatio } \\
\text { ns of law }\end{array}$ & N/A \\
\hline $\begin{array}{l}\text { UAS Service } \\
\text { Supplier(s) }\end{array}$ & $\begin{array}{l}\text { None - existent } \\
\text { and required }\end{array}$ & $\begin{array}{l}\text { None - } \\
\text { existent } \\
\text { and } \\
\text { required }\end{array}$ & $\begin{array}{l}\text { Some - } \\
\text { contract } \\
\text { s formed } \\
\text { with } \\
\text { NAS }\end{array}$ \\
\hline $\begin{array}{l}\text { Supplemental } \\
\text { Data Service } \\
\text { Providers }\end{array}$ & $\begin{array}{l}\text { None -existent } \\
\text { and required }\end{array}$ & $\begin{array}{l}\text { None - } \\
\text { existent } \\
\text { and } \\
\text { required }\end{array}$ & $\begin{array}{l}\text { Some - } \\
\text { with } \\
\text { UAS } \\
\text { Service } \\
\text { Supplier }\end{array}$ \\
\hline Regulators & $\begin{array}{l}\text { Yes - some } \\
\text { laws modified } \\
\text { to provide } \\
\text { alternative } \\
\text { ANSP's }\end{array}$ & $\begin{array}{l}\text { None }- \text { do } \\
\text { not } \\
\text { enforce } \\
\text { through } \\
\text { Local law }\end{array}$ & $\begin{array}{l}\text { Yes - } \\
\text { with } \\
\text { ANSP }\end{array}$ \\
\hline $\begin{array}{l}\text { ANSP's - (e.g. } \\
\text { NATS) }\end{array}$ & Yes & $\begin{array}{l}\text { None - } \\
\text { possibly } \\
\text { required }\end{array}$ & $\begin{array}{l}\text { With } \\
\text { Regulat } \\
\text { or - } \\
\text { (existing } \\
\text { data } \\
\text { require } \\
\text { ments) }\end{array}$ \\
\hline $\begin{array}{l}\text { Flight Information } \\
\text { Management } \\
\text { System (FIMS) } \\
\text { linked to ANSP }\end{array}$ & $\begin{array}{l}\text { None - existent } \\
\text { and required }\end{array}$ & $\begin{array}{l}\text { None } \\
\text { existent } \\
\text { and non- } \\
\text { required }\end{array}$ & $\begin{array}{l}\text { TBC- } \\
\text { Could/S } \\
\text { ervices } \\
\text { Architec } \\
\text { ture and } \\
\text { JV's }\end{array}$ \\
\hline $\begin{array}{l}\text { Manufacturer } \\
\text { Function }\end{array}$ & $\begin{array}{l}\text { Yes }- \text { new laws } \\
\text { regulating } \\
\text { standards, e.g. } \\
\text { EASA } \\
\text { categorisation }\end{array}$ & $\begin{array}{l}\text { None - } \\
\text { existent } \\
\text { and non- } \\
\text { required }\end{array}$ & $\begin{array}{l}\text { Yes - } \\
\text { with } \\
\text { UAS } \\
\text { Operato } \\
\text { rs }\end{array}$ \\
\hline $\begin{array}{l}\text { Other } \\
\text { Stakeholders } \\
\text { (Public, Public } \\
\text { Safety) }\end{array}$ & $\begin{array}{l}\text { None - existent } \\
\text { and required }\end{array}$ & $\begin{array}{l}\text { None- } \\
\text { existent } \\
\text { and } \\
\text { possibly } \\
\text { required }\end{array}$ & $\begin{array}{l}\text { None } \\
\text { existent } \\
\text { and non- } \\
\text { required }\end{array}$ \\
\hline
\end{tabular}

Further research will have to address the legal framework of 'solution developers' as well as how UTM intends to be harmonized across different jurisdictions, perhaps learning some of the lessons from the Single European ATM Research (SESAR) collaboration. Once the question of how to harmonize has been addressed, the next significant challenge is understanding what level of harmonization is required between stakeholders and states alike. In the EU, there is not always complete harmonization of laws because states are given some degree of discretion. 

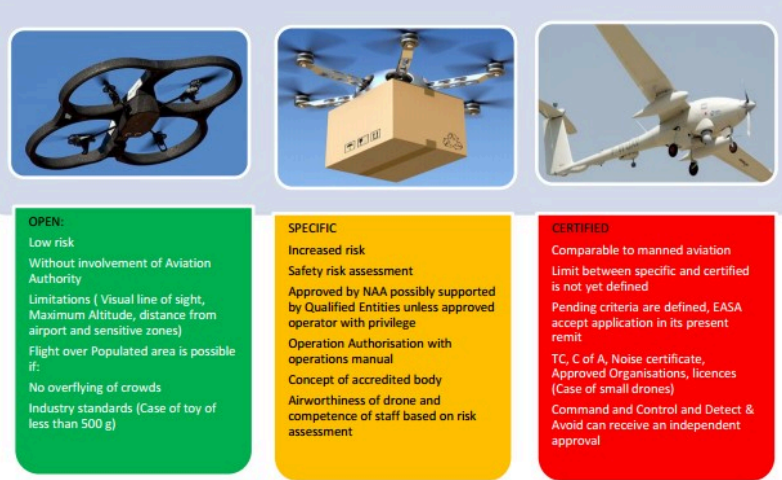

Figure 1: EASA regulations 2021 [12]

The notional US UTM architecture below demonstrates many different stakeholders that will all have varying degrees of legal interest and accountability. It is going to be very interesting to see how different models of UTM develop and mature in different jurisdictions. At this moment it is very difficult to comprehend and reconcile how there's going to be global harmonisation of UTM architectures. As we have seen above, the FAA and EASA are approaching this in very different ways, yet seeking the same end goal. It is without doubt the case, that other jurisdictions will also approach UTM architectures differently (as is the case in U-space and the UK open access UTM) as shoin in Fig. 2 , because they view risk differently and assess risk according to their own defined principles. The reason why risk is so important is because all stakeholders are seeking a safe integrated platform where manned and unmanned aviation can coexist.

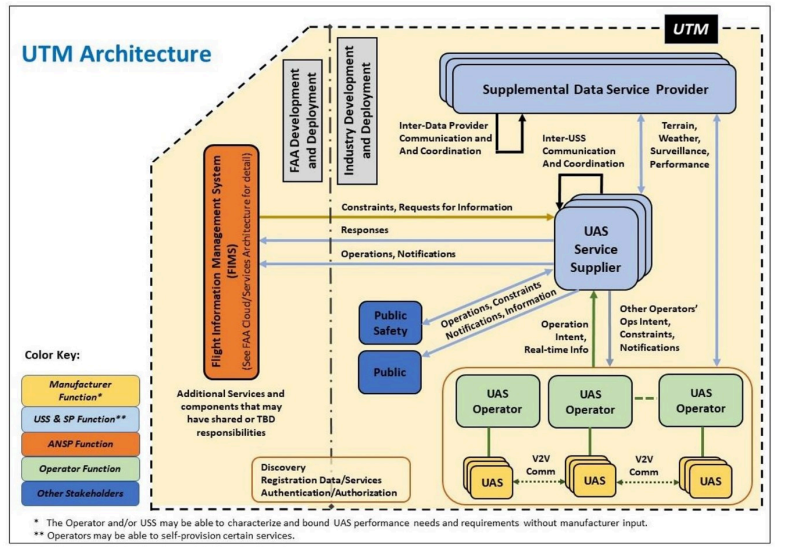

Figure 2: FAA notional UTM architecture version 2 [15]

\section{UTM SYSTEM}

The demands of a UTM system will be extremely complicated, which means that the law and the regulatory framework must be simple to enact and understand by all stakeholders. This presents a significant challenge and legislatures should not be quick to implement bad law, which may have a significant impact upon the development of a nascent industry. By way of example, the drone industry in different jurisdictions state that poor drone law forces innovation and industry to move to other jurisdictions which are less complicated and often equally less mature with respect to drone regulation-

"American laws and regulations governing the flight of commercial drones are overly restrictive, unnecessarily stifle valuable innovation, and must be revised to ensure that the true potential of drone technology can be realised [15]."

Laws and regulations will have to be balanced and well considered to address the flight of drones amongst all stakeholders, but UAS Service Suppliers appear to be key as a central function according to the FAA. When taking into consideration the notional UTM architecture in Figure 2: FAA notional UTM architecture above, a UTM system must legally and contractually provide amongst other things:

1. real-time information in relation to airspace constraints (predominantly low airspace $\geq 400$ feet Above Ground Level);

2. real-time information for all stakeholders;

3. other services may include:
a. airspace design;
b. airspace geo-fencing;
c. separation management;
d. weather mapping and forecasting;
e. wind mapping and forecasting;
f. routing selection;
g. contingency planning and management.

A UTM platform provider, regardless of the services provided, would have to be legally mandated by a regulator to provide those services (through appropriate legislation). This, in isolation, raises many legal issues, which may include, but not be limited to, actual drafting of relevant laws that affect fair selection and bidding, minimum operational capability, legal liability as well as 'state reliance' versus 'federal engagement.' Additionally, a legal framework will have to be designed that establishes and identifies services, but also:

4. defines what "UTM" actually is;

5. is consistent with existing complex regulatory frameworks;

6. defines roles and responsibilities of all various stakeholders;

7. defines information architecture;

8. defines data exchange protocols;

9. defines software functions;

10. defines necessary infrastructure;

11. defines interoperability, for example between two different low altitude airspace jurisdictions.

To make a finer point, at the moment there is no definition of "Services" that has to be provided by a UAS Service Supplier. Additionally, if two UTM companies are operating in the same airspace, who has access to what information? How is that airspace shared? How is the conflict between different UTM companies in the same airspace going to be managed as is envisaged by EASA's current U-space opinion to ensure a competitive environment [5]. This level of detail must be mandated in law to provide some certainty. Furthermore, the obligation to share information must be clearly defined because much of UTM will be premised upon knowing how to identify a UAS. What is the information required to identify a UAS? How is the identification of the UAS obtained? Why is the identification of the UAS protected? How is the source of the information trustworthy? As drones travel across different geographies, will trustworthy data differ? If so, how is that differential defined.

By extension EASA are developing an Artificial Intelligence (AI) roadmap in aviation [16] that seeks to develop the concept of trustworthiness. This is certainly another relevant aspect of disruptive technology that will push the boundaries of the development of the legal framework of a UTM. There are 
numerous questions that shall require legal answers that include a determination of how AI systems and machine learning systems are going to be certified. Additionally, how will AI effect standards and protocols to ensure and cement levels of safety within air transport systems as well as ensuring that 'ethics' are properly considered and integrated?

\section{CONCLUSION}

It must be clear by all stakeholders of what their respective legal obligations and responsibilities are. This is of particular importance to 'solutions developers' to ensure their systems are compliant with regulatory requirements and aligned with their legal accountabilities. Fundamentally, a consistent approach is required, but this is going to be challenged by differing opinions in relation to the interpretation of law, legal risk and the competing interests of UTM in different jurisdictions. This is very evident by the UTM industry at present as conventional aviation law is challenged. There are currently approximately 90 different companies globally that provide some form of UTM solution.

Having reviewed the existing legal framework in a number of different jurisdictions as it pertains to UAS, it is apparent that much work still needs to be done to provide certainty to all stakeholders that operate within a UTM system. The legal obligations for many stakeholders remain unclear because there is a divergence between the understanding and purpose of what law is required and the purpose of forming policy. This is a very complex environment that requires a complex solution that is easy for all stakeholders to understand and follow. Many stakeholders do not have an aviation background. One has to bear in mind that manned aviation to get to where it is today has had the benefit of at least 100 years of legal and regulatory development and iteration. The challenge with UAS is that the pace of change and development has and remains far greater than any regulator could envisage.

The intention of this paper is to identify a number of issues that require further investigation and clarification in order to influence how the legal framework of a UTM can be developed in the future. The level of influence required is by no means determinative as it will very much depend upon how all stakeholders view and adapt their risk profiles in order to ensure safe airspace for all users. The future of UTM is indeed very exciting and it will be an opportunity for regulators to take market advantage and seize upon the broad opportunities that UAS can offer those jurisdictions. However, this must be predicated on a predictable, unambiguous and thoughtful piece of legislation that relates to the roles and responsibilities of all stakeholders within a UTM framework. The potential impact on the drone industry is significant if a jurisdiction does not achieve the right balance.

\section{REFERENCES}

[1]. ICAO, "UTM Guidance - UTM - A Common Framework with Core Boundaries for Global Harmonization - Edition 2," International Civil Aviation Organisation, [Online]. Available:

https://www.icao.int/safety/UA/Documents/UTMFramework\%20Edition\%202.pdf. [Accessed $20 \quad 07$ 2020].

[2]. Federal Aviation Administration, "Concept of Operations v2.0," FAA, [Online]. Available: https://www.faa.gov/uas/research_development/traffic_m anagement/media/UTM_ConOps_v2.pdf. [Accessed 20 07 2020].

[3]. European Union Aviation Safety Agency, "High-level regulatory framework for the U-space," EASA, [Online]. Available:

https://www.easa.europa.eu/sites/default/files/dfu/Opinio n\%20No\%2001-2020.pdf. [Accessed 2007 20].
[4]. L. B. M. Roger Clarke, "The regulation of civilian drones' impacts on public," Computer Law \& Security Review, vol. 30, pp. 263-285, 2014.

[5]. E. U. A. S. Agency, "Opinion No 01/2020 High-level regulatory framework for the U-space," 13032020. [Online].

Available: https://www.easa.europa.eu/sites/default/files/dfu/Opinio n\%20No\%2001-2020.pdf. [Accessed 2107 20].

[6]. European Union Aviation Safety Agency, "U-SPACE REGULATORY FRAMEWORK WORKSHOP 14-15 MAY 2019 - COLOGNE SUMMARY OF CONCLUSIONS," EASA, 1505 2019. [Online]. Available:

https://www.easa.europa.eu/sites/default/files/dfu/Uspace $\% 20$ workshop $\% 20$ -

$\% 20$ summary $\% 20$ of $\% 20$ conclusions $\% 20 \% 28$ final $\% 29$.p df. [Accessed 2007 2020].

[7]. FAA and NASA, "Traffic Management Research Plan," $17012017 . \quad$ [Online]. Available: https://www.faa.gov/uas/research_development/traffic_m anagement/media/FAA_NASA_UAS_Traffic_Managem ent_Research_Plan.pdf. [Accessed 2107 2020].

[8]. Civil Aviation Authority, "Regulatory challenges for innovation in aviation - Guidance for innovators on addressing regulatory challenges and trialling your solution," [Online]. Available: https://www.caa.co.uk/Our-work/Innovation/Regulatorychallenges-for-innovation-in-aviation/. [Accessed 2107 2020].

[9]. UK Parliament, "Air Traffic Management and Unmanned Aircraft Bill [HL] 2019-21," www.parliament.uk, [Online]. Available: https://services.parliament.uk/Bills/2019-

21/airtrafficmanagementandunmannedaircraft.html. [Accessed 2107 2020].

[10]. UAV Coach, "Master List of Drone Laws (Organized by State \& Country)," [Online]. Available: https://uavcoach.com/drone-laws/. [Accessed 2107 2020].

[11]. R. R. a. C. Gee, "Will local authorities become airspace planners?," Local Government Lawyer, p. 1, 07022020.

[12]. Callum, "Grey Arrows Drone Club," 12 2019. [Online]. Available: https://greyarro.ws/t/new-easa-drone-rules-1july-2020-discussion/11396/43. [Accessed 2107 2020].

[13]. EUR-LEX, "Commission Implementing Regulation (EU) 2020/746 of 4 June 2020 amending Implementing Regulation (EU) 2019/947 as regards postponing dates of application of certain measures in the context of the COVID-19 pandemic (Text with EEA relevance)," 0406 $2020 . \quad$ [Online]. Available: http://data.europa.eu/eli/reg_impl/2020/746/oj. [Accessed $21072020]$

[14]. European Union Aviation Safety Agency, "Drones regulatory framework timeline," [Online]. Available: https://www.easa.europa.eu/drones-regulatoryframework-timeline. [Accessed 2107 2020].

[15]. J. O. A. W. Steve Calandrillo, "Deadly Drones? Why FAA Regulations," Stanford Technology Law Review, vol. 23:1, pp. 183-251, 2020.

[16]. European Union Aviation Safety Agency, "Artifical Intelligence Roadmap - A human-centric approach to AI in aviation," [Online]. Available: file://C:/Users/User/AppData/Local/Microsoft/Windows/ INetCache/Content.Outlook/PHFT302E/EASA-AIRoadmap-v1.0.pdf. [Accessed 2207 2020]. 


\title{
Cranfield University
}

\section{CERES https://dspace.lib.cranfield.ac.uk}

2020-11-18

\section{The legal framework of UTM for UAS}

\author{
Ryan, Richard
}

\section{IEEE}

Ryan R, Al-Rubaye S, Braithwaite G, Panagiotakopoulos D. (2020) The legal framework of UTM for UAS. In: 2020 AIAA/IEEE 39th Digital Avionics Systems Conference (DASC), 11-15 October 2020, San Antonio, TX, USA

https://doi.org/10.1109/DASC50938.2020.9256577

Downloaded from Cranfield Library Services E-Repository 